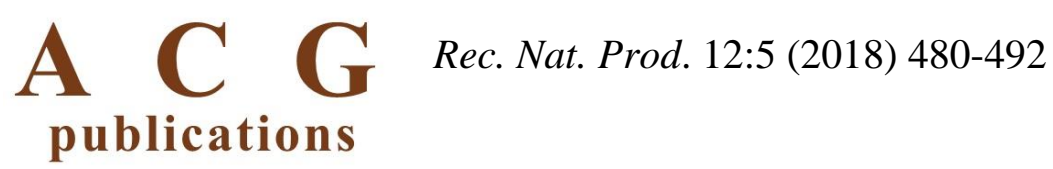

records of natural products

\title{
ß-Amyrin Rich Bombax ceiba Leaf Extract with Potential Neuroprotective Activity against Scopolamine-Induced Memory Impairment in Rats
}

\author{
Nada M. Mostafa ${ }^{\bullet *}$ \\ Department of Pharmacognosy, Faculty of Pharmacy, Ain Shams University, Cairo 11566, Egypt
}

(Received October 05, 2017; Revised January 08, 2018; Accepted January 11, 2018)

\begin{abstract}
The neuroprotective potential of Bombax ceiba L. (Malvaceae) leaves extract (BCLE) was evaluated herein for the first time. Memory impairment was induced in rats by scopolamine (SC) administration for seven days $(1.5 \mathrm{mg} / \mathrm{kg} / \mathrm{day}$, i.p.). BCLE $(200 \mathrm{mg} / \mathrm{kg})$ or donepezil $(1 \mathrm{mg} / \mathrm{kg})$ was administered orally a week before and then concomitantly with SC for another week. BCLE improved the rats' behaviors estimated by Morris water maze and passive avoidance tests, where the rats showed prolongation in time spent in platform quadrant and step-through latency, respectively, compared to administration of SC alone. BCLE also ameliorated the antioxidant parameters (Catalase with malondialdehyde (MDA), and the SC-induced elevation of acetylcholinesterase (AChE) in rats' brain tissues. Histopathological studies supported the above results. BCLE phytochemical study resulted in isolation and structural elucidation of $\beta$-sitosterol linoleate (first to be isolated from the genus) and $\beta$-amyrin. Twenty-seven compounds (93.35\%) were identified in BCLE by gas chromatography/mass spectrometry (GC/MS). The major components were triterpenoids (69.82\%), composing mainly of $\beta$-amyrin (45.28\%), lupeol (15.03\%) and olean-12-en-3-one (6.27\%), in addition to fatty acid esters $(13.37 \%)$ and steroids $(7.75 \%)$, which were rich in methyl palmitate $(9.87 \%)$ and stigmasterol acetate $(4.91 \%)$, respectively. These compounds may be responsible for ameliorating the SC-induced oxidative stress and cholinergic dysfunction.
\end{abstract}

Keywords: Bombax ceiba; GC/MS; $\beta$-amyrin; neuroprotective; scopolamine. (C) 2018 ACG Publications. All rights reserved.

\section{Introduction}

Bombax ceiba L. (Malvaceae) has been used traditionally for blood purification, lightening of skin in acne and pigmentation, treatment of wounds, leucorrhoea, weakness, cold and coughs [1]. In addition, it provides nutritional values as it has some edible parts like many other Malvales plants [2, 3]. B. ceiba is characterized phytochemically by the presence of flavonoids, xanthones, quinines, naphthoquinones, triterpenes, sterols, hydrocarbons, fatty acids and their esters [4, 5]; and

*Corresponding author: E-Mail: nadamostafa@pharma.asu.edu.eg; Phone:+2-01025666872 Fax:+2-0224051107 
pharmacologically by various activities such as antimicrobial [6], hypotensive, hypoglycemic [7], antioxidant [8-11], cytotoxic [12], antiproliferative [10], and antitumor [11] activities.

Alzheimer disease is a progressive disorder that involves neurodegeneration of the brain tissues, decrease in acetylcholine levels, and impairment of memory and cognition abilities [13]. Scopolamine (SC) is an anti-muscarinic agent that causes Alzheimer-type dementia by producing a status of oxidative stress and increasing the levels of AChE causing a decline in the cholinergic activity [14]. However, Donepezil is a selective AChE inhibitor that has been approved as a drug for treating Alzheimer by elevating the brain cholinergic transmission and decreasing the amyloid $\beta$-fibrils toxic forms $[15,16]$.

Thus, the present study was conducted to evaluate BCLE antioxidant and neuroprotective activities, as compared to donepezil, against SC-induced memory impairment and learning deficit in rats. This was supported by behavioral, neurochemical and histopathological studies. In addition, BCLE was investigated phytochemically and for the first time by GC/MS analysis, in order to identify possible components that may be responsible for the observed effects.

\section{Materials and Methods}

\subsection{Plant Material}

Bombax ceiba L. (Malvaceae) leaves were collected from El-Orman Botanical Garden, Egypt and authenticated by Mrs. Trease Labib, Plant Taxonomy Consultant at the Egyptian Ministry of Agriculture. A voucher specimen (PHG-P-BC-2) was kept at the Department of Pharmacognosy, Faculty of Pharmacy, Ain Shams University, Cairo, Egypt.

\subsection{Chemicals}

Scopolamine (SC) was obtained from Sigma Aldrich, MO, USA. Donepezil ${ }^{\circledR}$ tablets were purchased from a local pharmacy. For measuring the neurochemical parameters; catalase, Malondialdehyde (MDA), and acetylcholinesterase (AChE) kits were purchased from Bio-Diagnostics Company, Dokki, Giza, Egypt. All chemicals used in this study were of analytical grade.

\subsection{Extract Preparation}

The fresh leaves of $B$. ceiba $(1 \mathrm{~kg})$ were extracted with neat methanol till complete exhaustion. The combined methanol extracts were distilled off at $45^{\circ} \mathrm{C}$ in a rotary evaporator till complete dryness, and then lyophilized to obtain a powdered residue that was stored in refrigerator till biological evaluation. For GC/MS analysis, BCLE was dissolved in the least amount of distilled water and fractionated with hexane. The hexane fraction was kept in sealed vials in the refrigerator for subsequent evaluation.

\subsection{Compounds Isolation and Identification}

The concentrated total methanol extract was mixed with sufficient amount of activated charcoal with continuous stirring for an hour to remove most of the chlorophyll. The extract was then filtered and distilled off at $45^{\circ} \mathrm{C}$ in rotary evaporator till complete dryness. The obtained residue $(10 \mathrm{~g})$ was dissolved in the least amount of methanol, where a heavy yellow precipitate was formed that was isolated and dissolved in dichloromethane, then subjected to repetitive preparative silica TLC using solvent system Hexane: Dichloromethane (7: 3) to yield compound 1 ( $\beta$-sitosterol linoleate, $7 \mathrm{mg}$ ) that gave a pinkish violet color upon spraying with vanillin-sulphuric reagent and heating at $100^{\circ} \mathrm{C}$.

BCLE methanol-soluble fraction was further fractionated by a Diaion HP-20 column chromatography (100 L, 4.5 i.d. cm). The elution process started with distilled water, then $25 \%, 50 \%$ 
and $75 \%$ methanol in water, followed by neat methanol and finally acetone to ensure complete elution. Similar fractions were pooled together according to the results obtained from TLC analysis of the eluted fractions, then dried in vacuo at $45^{\circ} \mathrm{C}$ to yield six main fractions. The fraction eluted with neat methanol was reduced in volume using rotary evaporator at $45^{\circ} \mathrm{C}$, where needle crystals were precipitated and then washed with acetone to yield compound 2 ( $\beta$-amyrin, $20 \mathrm{mg}$ ). Structure elucidation was done by comparing the compounds ${ }^{1} \mathrm{H}-\mathrm{NMR}$ and APT-spectral data with literature.

\subsection{NMR Spectroscopy}

${ }^{1} \mathrm{H}-\mathrm{NMR}$ and APT-spectral data were measured in $\mathrm{CDCl}_{3}$ on Bruker Ascend 400 spectrometer, Avance BioSpin Inc., at 400 and $100 \mathrm{MHz}$, respectively. Chemical shifts, in ppm, were recorded using tetramethylsilane (TMS) as an internal standard.

\subsection{GC/MS Analysis}

Shimadzu GC/MS-QP2010 (Tokyo, Japan) was used to record the mass spectrum. It was equipped with a $30 \mathrm{~m}$ Rtx-5MS (Restek, USA) fused-bonded column $(0.25 \mathrm{~mm}$ i.d., $0.25 \mu \mathrm{m}$ film thickness) coupled to a quadrupole mass spectrometer (SSQ 7000; Thermo-Finnigan, Bremen, Germany) and having a split-splitless injector. The carrier gas (helium) flow rate was $1.41 \mathrm{~mL} / \mathrm{min}$. The column temperature was kept initially at $45^{\circ} \mathrm{C}$ for 2 minutes isothermal, programmed to $300^{\circ} \mathrm{C}(5$ ${ }^{\circ} \mathrm{C} / \mathrm{min}$ ) then kept at $300^{\circ} \mathrm{C}$ (isothermal) for 5 minutes. The injector temperature was $250{ }^{\circ} \mathrm{C}$. A filament emission current of $60 \mathrm{~mA}$, an ionization voltage of $70 \mathrm{eV}$, and $200^{\circ} \mathrm{C}$ ion source were applied. The sample was diluted (1\% v/v) and injected with a split mode of a ratio 1: 15 . Compound identification was based on mass spectral data (MS), comparing with published retention indices (RI) in NIST Mass Spectral Library, Wiley Registry of Mass Spectral Data, other published data [17-22] as well as co-chromatography with authentic samples.

\subsection{Animals}

Male Sprague-Dawley rats (150-200 g) were purchased from National Research Center (Dokki, Giza, Egypt) and acclimatized for at least 1 week in the animal house facility, Faculty of Pharmacy, Ain Shams University, Cairo, Egypt prior to the experiment. The rats were kept at $23 \pm 2{ }^{\circ} \mathrm{C}$ and supplied with standard food pellets and access to water ad libitum. The rat treatment protocol was approved by the Ethical Committee for Animal Use, Faculty of Pharmacy, Ain Shams University.

\subsection{Experimental Design}

Animals were divided into four groups of six rats each. Group 1: Control group received distilled water orally for 14 days. Group 2: received distilled water orally 1 week before scopolamine administration and then concomitantly with scopolamine $(1.5 \mathrm{mg} / \mathrm{kg} /$ day, i.p. $)$ for another week. Group 3 and 4: received donepezil ( $1 \mathrm{mg} / \mathrm{kg} /$ day) or BCLE $(200 \mathrm{mg} / \mathrm{kg} /$ day $)$, respectively orally 1 week before scopolamine administration and then concomitantly with scopolamine $(1.5 \mathrm{mg} / \mathrm{kg} / \mathrm{day}$, i.p.) for another week.

\subsection{Passive Avoidance Test}

It was done in two identical chambers, according to the method of Yang et al. (2013) [23]. One chamber was illuminated by a bulb, while the other was non-illuminated with stainless steel rods in the floor. A guillotine door was located between the two chambers. In the first trial (acquisition), the rats were placed in the lighted chamber and the door in-between was opened for $20 \mathrm{~s}$. As soon as the rat entered to the dark area, the door was automatically closed and a $0.5 \mathrm{~mA}$ electrical foot shock was 
delivered to the rat through the stainless steel rod for the duration of 3 seconds. Twenty-four hours later after this trial, the rats repeated the test for the retention trials by placing in the illuminated chamber and recording the time taken for each rat to enter the dark chamber as the latency times in both the acquisition and the retention trials, with a maximum of 300 seconds.

\subsection{Morris Water Maze}

The maze is a circular pool of $150 \mathrm{~cm}$ diameter, a height of $60 \mathrm{~cm}$ and filled with water at room temperature with a featureless inner surface. The tank was mounted in a dimly lit and in a sound-proof room with numerous visual cues. The pool was divided conceptually into four quadrants, and a platform of $12 \mathrm{~cm}$ diameter and height of $40 \mathrm{~cm}$ was placed in one of the water pool quadrants and was submerged $2 \mathrm{~cm}$ below the water surface so that it becomes invisible at the water level. The rats underwent a training period of four subsequent days, where each rat was put in water a different quadrant randomly each time and allowed to swim for 90 seconds till reaching the platform and in case it failed in finding the platform, the rat was put onto the platform for 30 seconds. These trials were repeated for each rat three times a day. After each trial, the animals were dried under an infrared lamp. The test was repeated on the fifth day (test trial) with the platform removed. The time of swimming in the quadrant of the removed platform and the number of crossing times to that quadrant were recorded using a video camera for three times for each rat.

\subsection{Preparation of Rats' Brain Tissues}

At the end of the study (14 days), the rats were anesthetized and sacrificed by decapitation. Their skulls were open onto iced isotonic saline. Sample brain tissues were fixed in $10 \%$ formalin in saline for histopathological examination. Other brain tissues were dissected out into striata, cortices, and hippocampi then $10 \%(\mathrm{w} / \mathrm{v})$ homogenates were prepared in isotonic saline for neurochemical analysis.

\subsection{Neurochemical Parameters}

Determination of catalase, lipid peroxidation expressed as MDA equivalents and acetylcholinesterase (AChE) activities in the rats' brain tissues were according to the kit manufacturer instructions (Bio-Diagnostics Company, Dokki, Giza, Egypt). Catalase was determined according to the method of Aebi (1984) [24] and was expressed as U/g tissue. MDA was determined according to the method of Ohkawa et al. (1979) [25] and was expressed as $\mu \mathrm{mol} / \mathrm{g}$ tissue, while AChE activity expressed as $\mathrm{nM} / \mathrm{min} / \mathrm{mg}$ tissue was determined according to Ellman et al. (1961) method [26]. The samples were run in triplicates and expressed as mean \pm SEM.

\subsection{Histopathological Examination}

Brain autopsy samples taken from different groups were fixed in $10 \%$ formalin in saline for 24 hours, washed with tap water then serial alcohol dilutions for dehydration. Specimens cleared in xylene were embedded in paraffin at 56 degrees for $24 \mathrm{~h}$. in a hot air oven. The tissue blocks were then sectioned, put onto glass slides, deparaffinized, and stained with hematoxylin and eosin stain. Light electric microscopy is used for examination [27].

\subsection{Statistical Results}

Data were expressed as mean \pm SEM, and then analyzed by one-way ANOVA followed by Tukey post hoc tests. Analyses and graphs were performed and sketched by GraphPad Prism version 5.01 software, California, USA. Results were considered statistically significant at $P<0.05$. 


\section{Results and Discussion}

Dementia was induced in rats by SC injection $(1.5 \mathrm{mg} / \mathrm{kg} / \mathrm{day}$, i.p. ) for 7 consecutive days. The neuroprotective activity of BCLE ( $200 \mathrm{mg} / \mathrm{kg}$, orally) was evaluated, for the first time, as compared to a reference drug (donepezil, $1 \mathrm{mg} / \mathrm{kg}$ orally) by administration a week before and then concomitantly with SC for another week.

\subsection{Morris Water Maze Test}

To test BCLE amelioration effect on SC-induced memory impairment, the rats went into Morris water maze test (Figure 1A-C). The SC-treated group demonstrated prolonged escape latency, spent the least amount of time $(-84 \%)$ in the platform quadrant and showed a significant decrease $(45.45 \%)$ in crossing times of the platform quadrant when compared to the control group. However, BCLEtreated rats were efficient in finding the platform quadrant, with increased crossing times and prolonged time spent in the platform quadrant (305.85\%, compared to the SC-group). BCLE effects were close to those of donepezil.

\subsection{Passive Avoidance Test}

The passive avoidance test (Figure 1D, E) was carried out to evaluate more of the rats' behavioral parameters. The SC-treated group showed a significant shortening in the step-through latency (-91.14\%, comparing to the control group). Both donepezil and BCLE treatments prolonged the SC-shortened latency with only -10.34 and $-13.76 \%$, respectively, as compared to the control group. In the acquisition trial, no differences in the latency times were observed among the tested groups. These results proved that BCLE ameliorated the rats' behavioral parameters.

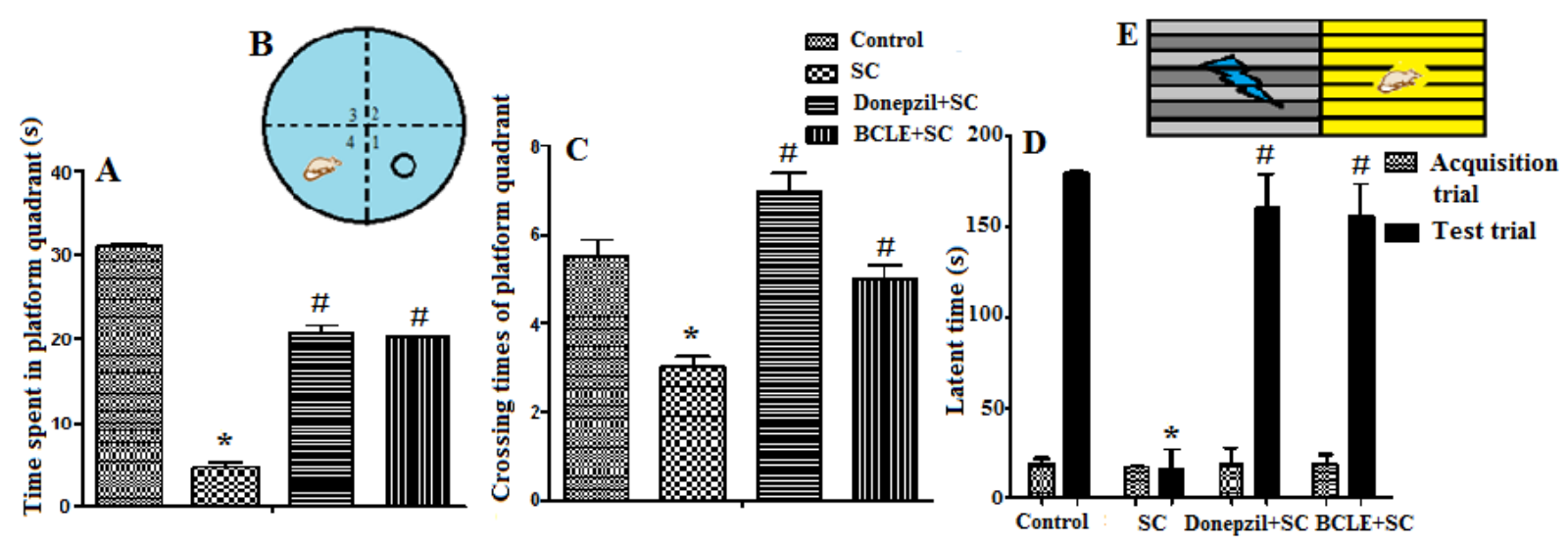

Figure 1. Effect of BCLE on Morris water maze (A, C) and passive avoidance tests (D), which were represented graphically in $\mathrm{B}$ and $\mathrm{E}$, respectively. Data were expressed as mean $\pm \mathrm{SEM}, n=6$. ${ }^{*} P<$ 0.05 , significant difference from the control group. ${ }^{\#} P<0.05$, significant difference from the SCtreated group.

\subsection{Antioxidant Parameters}

The effect on the antioxidant parameters was evaluated in rats' brain tissues through measuring the catalase activity and the malondialdehyde (MDA) equivalents (Figure 2A, B). SC treatment decreased the catalase activity and increased MDA in rats' hippocampus by 18.25 and $55.27 \%$, respectively, when compared to the control group. While, both donepezil and BCLE increased the SC- 
induced reduction in catalase activity by 46.04 and $9.25 \%$, respectively, and decreased the MDA equivalents by 31.11 and $75.10 \%$, respectively, as compared to SC treatment alone. Worth of mentioning that MDA equivalent of BCLE-treated group was significantly reduced compared to control group by $61.34 \%$, which indicates a powerful reduction in lipid peroxidation and potentially significant antioxidant effect of BCLE. The MDA equivalent of the donepezil-treated group was close to the control group with a percent change of $6.95 \%$.

\subsection{Acetylcholinesterase (AChE) Activity}

The acetylcholine content in rats' brain hippocampus tissue was evaluated through measuring the AChE activity (Figure 2C). SC treatment significantly increased the AChE by $87.5 \%$ compared to control group. Both donepezil and BCLE significantly decreased the SC-induced elevation in AChE levels by 36.67 and $48 \%$, respectively. BCLE administration recovered the AChE levels back to normal values (-2.5\%, compared to the control group).

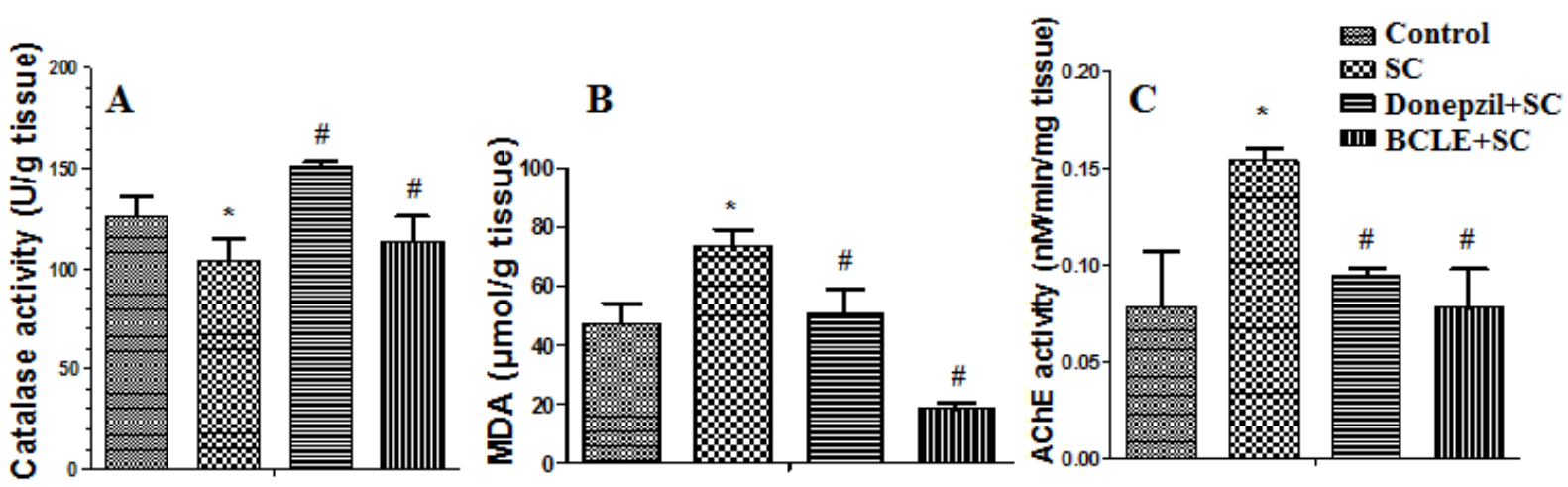

Figure 2. Effect of BCLE on antioxidant parameters (catalase (A), MDA(B)) and AChE activity (C) in SC-induced memory impairment. Data were expressed as mean \pm SEM, $n=6 .{ }^{*} P<0.05$, significant difference from the control group. ${ }^{\#} P<0.05$, significant difference from the SC-treated group.

\subsection{Histopathological Studies}

Further confirmation was done by histopathological studies of the rats' brains (Figure 3). In the control and BCLE-treated groups, no histopathological alterations were observed and normal histological structure of the neurons in the cerebral cortex, subiculum, fascia dentate and hilus of the hippocampus, as well as the striatum, were recorded. Similar results were shown in the donepeziltreated group except for some nuclear pyknosis and degeneration in the striatum neuronal cells.

Intraperitoneal administration of $1.5 \mathrm{mg} / \mathrm{kg}$ of $\mathrm{SC}$ daily to rats for seven consecutive days has altered the normal features of the brain tissues, where both nuclear pyknosis and degeneration were detected in the neurons of the cerebral cortex, fascia dentate, hilus of the hippocampus. There was no histopathological alteration in the neurons of the subiculum of the hippocampus, while the striatum showed small-sized eosinophilic plagues formation with nuclear pyknosis and degeneration in the neuronal cells. 


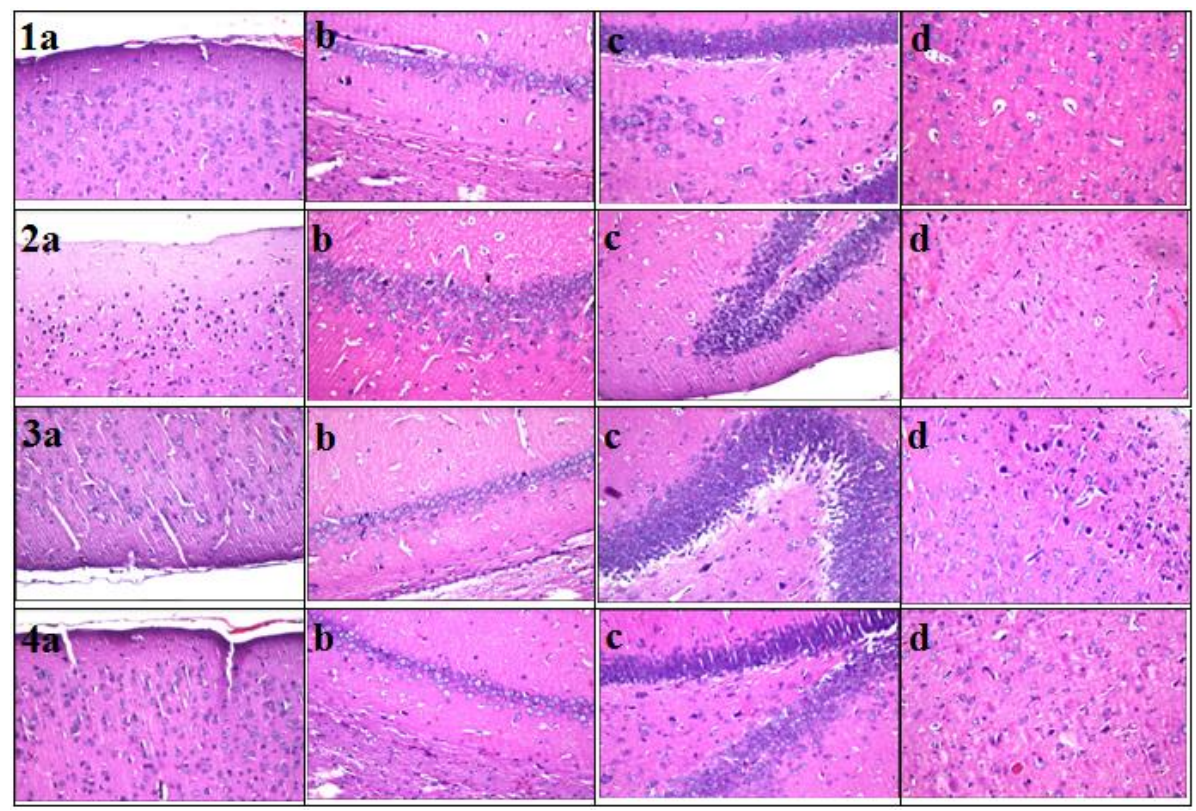

Figure 3. Hematoxylin and Eosin (H \& E) stained microphotographs of (a) cerebral cortex, (b) subiculum, (c) fascia dentate, hilus of the hippocampus, and (d) striatum of rats' brains. Control group (1) showed no histopathological alteration, SC group (2) showed nuclear pyknosis, degeneration (2a, c, d), and small size eosinophilic plagues formation (2d). Donepezil (3) or BCLE groups (4) recovered the normal tissue architecture.

\subsection{Phytochemical Analysis}

Phytochemical investigation of BCLE resulted in isolation and structural elucidation of $\beta$ sitosterol linoleate and $\beta$-amyrin. The former was isolated for the first time from the genus. Their structures (Figure 4) were elucidated using spectroscopic techniques and comparing with literature data.

$\beta$-Sitosterol linoleate (1): Colorless oil (7 mg), ${ }^{1} \mathrm{H}-\mathrm{NMR}$ (400 MHZ, $\left.\mathrm{CDCl}_{3}\right) \delta$ ppm: 5.3-5.4 ( $m$, $\left.\mathrm{H}-5,9^{\prime}, 10^{\prime}, 12^{\prime}, 13^{\prime}\right), 3.51(1 \mathrm{H}, m, \mathrm{H}-3), 2.79\left(t, J=6 \mathrm{~Hz}, \mathrm{H}-11^{\prime}\right), 2.32\left(m, \mathrm{H}-2^{\prime}\right), 2.02-2.08\left(m, \mathrm{H}-8^{\prime}\right.$, $\left.14^{\prime}\right), 1.63\left(m, \mathrm{H}-3^{\prime}\right), 1.28-1.33\left(m, \mathrm{H}-4^{\prime}, 5^{\prime}, 6^{\prime}, 7^{\prime}, 15^{\prime}, 16^{\prime}, 17^{\prime}\right), 1.04(3 \mathrm{H}, s, \mathrm{H}-29), 0.94(3 \mathrm{H}, d, J=6$ $\mathrm{Hz}, \mathrm{H}-19), 0.83-0.92$ ( $\left.m, \mathrm{H}-18^{\prime}, 24,26,27\right), 0.7$ (3H, $\left.s, \mathrm{H}-28\right)$. APT-NMR (100 MHz, $\left.\mathrm{CDCl}_{3}\right) \delta$ ppm: 173.25 (C-1'), 139.74 (C-5), 130.23 (C-9'), 130.08 (C-13'), 127.99 (C-10'), 127.86 (C-12'), 122.56 (C6), 73.73 (C-3), 56.64 (C-14), 56.05 (C-17), 50.05 (C-9), 45.76 (C-22), 42.26 (C-13), 42.26 (C-4), 39.63 (C-12), 38.12 (C-1), 36.59 (C-10), 36.16 (C-18), 34.72 (C-2'), 33.96 (C-20), 31.93 (C-2), 31.92 (C-16'), 31.88 (C-7), 31.88 (C-8), 29.71-29.10 (C-4', 5', 6', 7', 15'), 29.60 (C-25), 28.25 (C-16), 27.83 (C-8'), 27.20 (C-14'), 26.10 (C-21), 25.64 (C-3'), 25.06 (C-11'), 24.30 (C-15), 23.08 (C-23), 22.70 (C17'), 21.04 (C-11), 19.82 (C-26), 19.33 (C-27), 19.04 (C-19), 18.79 (C-28), 14.12 (C-18'), 11.99 (C24), 11.86 (C-29). These data were in accordance with those reported in literature by Chaturvedula and Prakash, 2012 [28] and Yang et al., 2003 [29] for sitosterol and linoleate moieties, respectively.

$\beta$-Amyrin (2): Colorless needle crystals (20 mg), ${ }^{1} \mathrm{H}-\mathrm{NMR}\left(400 \mathrm{MHZ}, \mathrm{CDCl}_{3}\right) \delta$ ppm: $5.2(1 \mathrm{H}, t$, $J=3.5, \mathrm{H}-12), 3.25(1 \mathrm{H}, d d, J=4.4,11, \mathrm{H}-3), 1.92\left(m, \mathrm{H}_{\beta}-19\right), 1.89\left(m, \mathrm{H}_{\beta}-15\right), 1.79(m, \mathrm{H}-22), 1.71$ $\left(m, \mathrm{H}_{\beta}-16\right), 1.16(3 \mathrm{H}, s, \mathrm{H}-27), 1.02(3 \mathrm{H}, s, \mathrm{H}-26), 0.99(3 \mathrm{H}, s, \mathrm{H}-24), 0.96(3 \mathrm{H}, s, \mathrm{H}-26), 0.89(6 \mathrm{H}, s$, $\mathrm{H}-29,30), 0.86(3 \mathrm{H}, s, \mathrm{H}-25), 0.81(3 \mathrm{H}, s, \mathrm{H}-23), 0.69(1 \mathrm{H}, d, J=11, \mathrm{H}-5)$. APT-NMR $(100 \mathrm{MHz}$, $\left.\mathrm{CDCl}_{3}\right) \delta$ ppm: 145.18 (C-13), 121.64 (C-12), 79.03 (C-3), 55.17 (C-5), 47.63 (C-9), 47.24 (C-18), 46.83 (C-19), 41.73 (C-14), 39.81 (C-8), 38.60 (C-1), 38.76 (C-4), 37.10 (C-22), 36.94 (C-10), 34.73 (C-21), 33.35 (C-29), 32.65 (C-17), 32.49 (C-7), 31.09 (C-20), 28.40 (C-28), 28.08 (C-23), 27.23 (C- 
2), 26.95 (C-15), 26.12 (C-16), 26.01 (C-27), 23.69 (C-30), 23.54 (C-11), 18.38 (C-6), 16.80 (C-26), $15.58(\mathrm{C}-25), 15.48(\mathrm{C}-24)$. These data were in accordance with those reported in literature [30].

\subsection{GC-MS Analysis}

The GC-MS analysis of BCLE was carried out for the first time. It revealed the presence of triterpenoids and their acetate esters (69.82\%) which were composed mainly of $\beta$-amyrin $(45.28 \%)$, lupeol $(15.03 \%)$ and olean-12-en-3-one (6.27\%). Fatty acid esters $(13.37 \%)$ were rich in methyl palmitate $(9.87 \%)$, while steroidal compounds $(7.75 \%)$ were rich in stigmasterol acetate $(4.91 \%)$, as shown in Table 1. The structures of the major compounds identified in the GC-MS analysis are demonstrated in Figure 4.

Table 1. Chemical composition of B. ceiba leaves extract (BCLE)

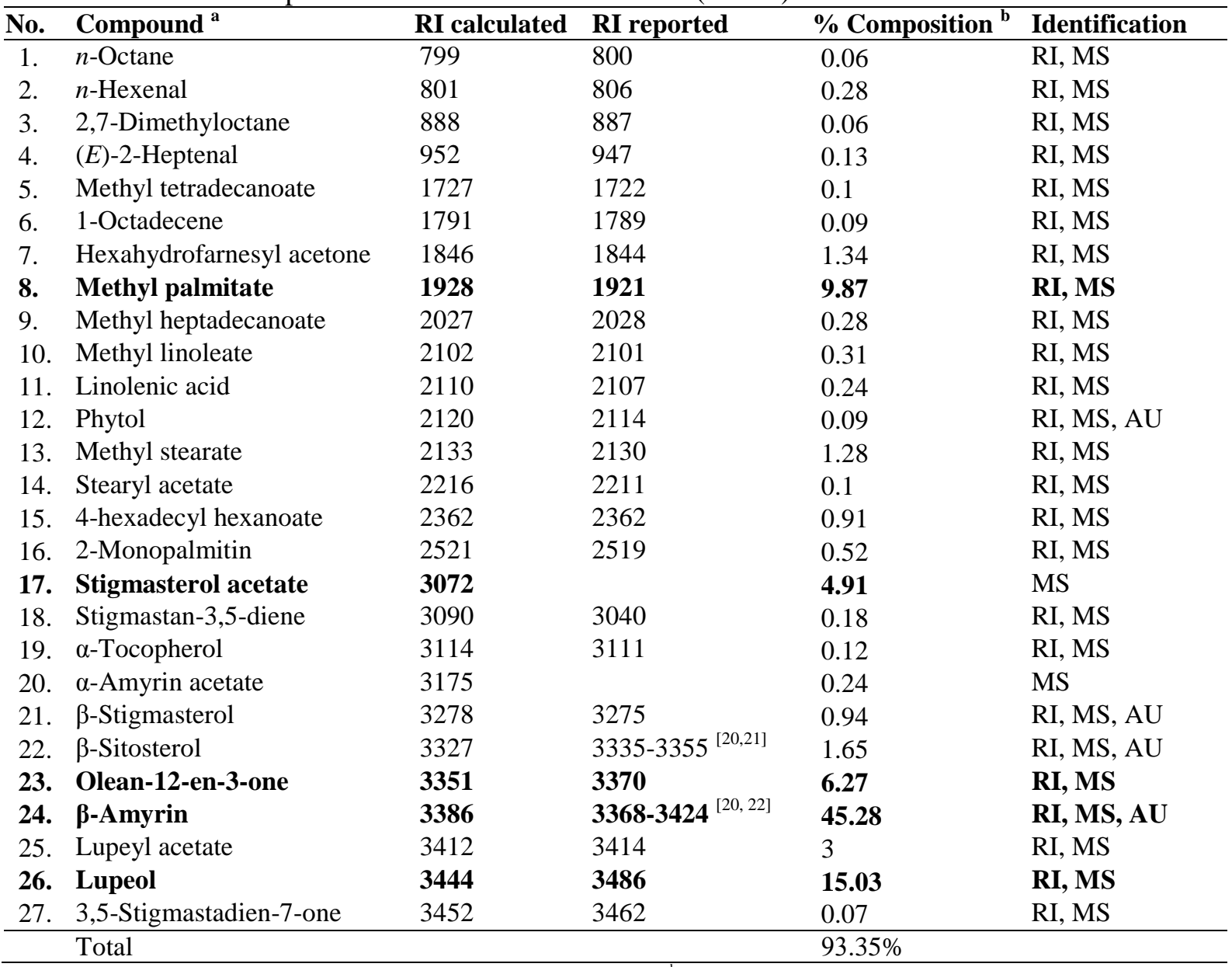

${ }^{a}$ Numbering according to elution order on Rtx-5MS fused bonded column, ${ }^{b}$ Percentages are the mean of three analyses. Identification was based on comparing RI: published retention indices in Wiley Registry of Mass Spectral Data (8th edition), NIST Mass Spectral Library and other published data [17-22], MS: mass spectral data and AU: co-chromatography with authentic samples. Major components were highlighted in bold.

The presence of a wide range of data reported for the retention indices of some sterols and/ or triterpenoids can be attributed to the differences in experimental conditions, column properties and size, in addition to measurement errors [31]. 

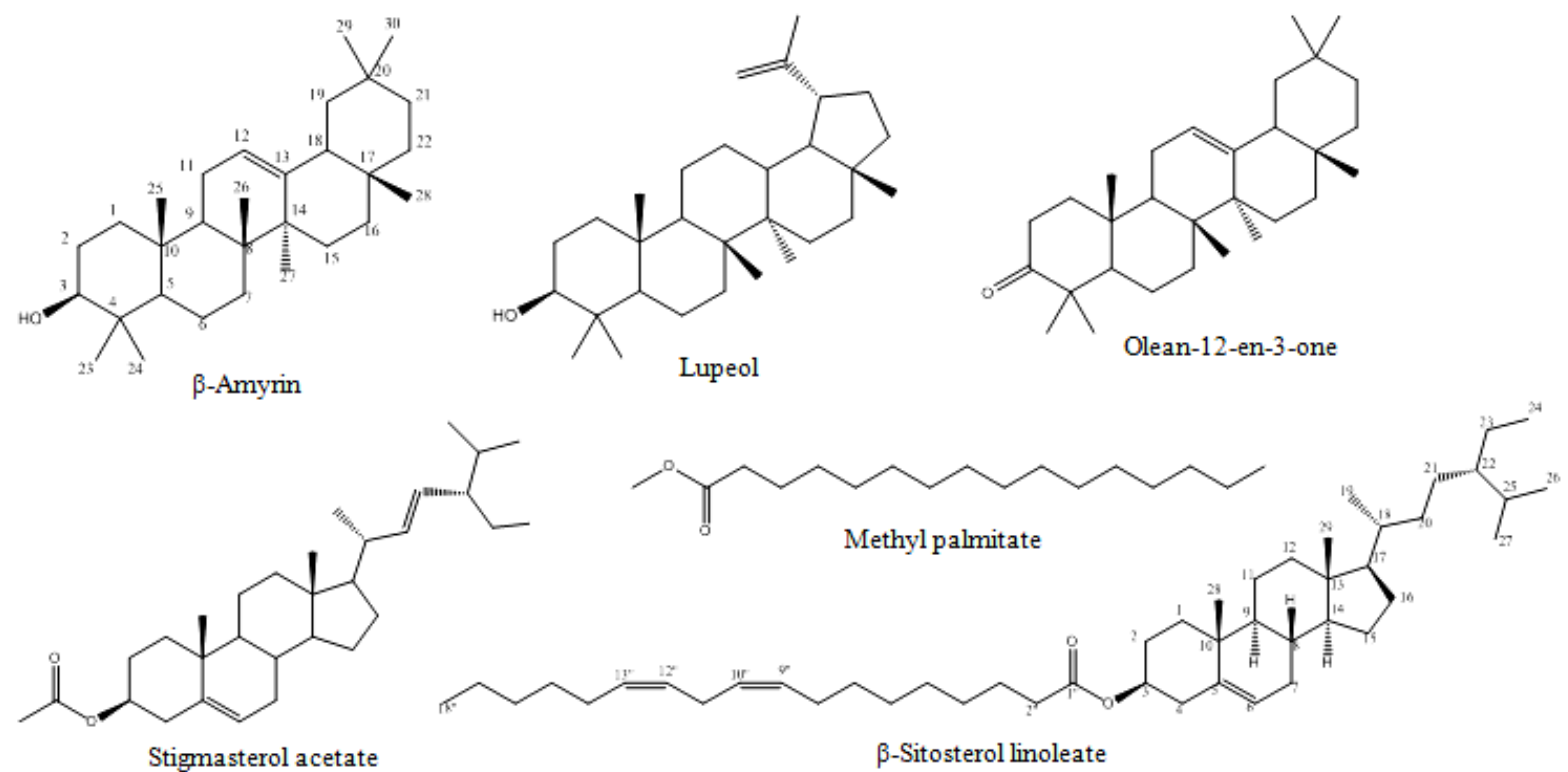

Figure 4. Major compounds identified and/or isolated from BCLE.

Alzheimer is a neurodegenerative disease with progressive disorders in the brain leading to dementia and characterized by a functional decline in memory, disturbance in behavior and decrease in the level of brain acetylcholine [32,33]. SC is an antagonist for the cholinergic receptors. It is frequently used in experimental models of memory impairment and dementia of Alzheimer type. It acts by blocking the cholinergic neurotransmission leading to impaired cognition and dysfunction [34]. Different classes of acetylcholinesterase (AChE) inhibitors, such as donepezil, have been used in the symptomatic treatment of Alzheimer. Yet, their non-selectivity, cholinergic adverse effects, and hepatotoxicity limit their use and lead our concern to phytochemicals and herbal supplements for a safer management of Alzheimer [35].

The neuroprotective and cognition-enhancing abilities of BCLE were investigated against SCinduced memory deficit in rats through estimating the behavioral, biochemical parameters and histological studies. Morris water maze was experimented on rats to test the amelioration effect on spatial memory and learning abilities [16]. BCLE-treated group showed a significant improvement in spatial learning through efficiency in finding the platform quadrant, as evident from increased crossing times and prolonged period of time spent in the platform quadrant. The memory enhancement effects demonstrated by the extract-treated group were closely similar to those of the drug donepezil. This proves the potential amelioration effects of BCLE on SC-induced impairment of spatial memory.

The passive avoidance test was carried out to study the effect on long-term memory and to evaluate the processes of acquisition, retention, and retrieval of the learned abilities [36]. BCLE showed prolongation in the SC-shortened step-through latency. These results proved that BCLE ameliorated the rats' behavioral parameters.

To elucidate BCLE biochemical mechanism of anti-amnesia, the antioxidant parameters (catalase and MDA) were evaluated along with the AChE activities in rats' brain tissues. Catalase is one of the antioxidant defense enzymes capable of scavenging free radicals and reducing oxidative stress in brain tissues by breaking down hydrogen peroxide and protecting our bodies against reactive hydroxyl radicals [37]. MDA is the end product in the process of peroxidation of lipids [38], thus it is a potential marker of oxidative stress. SC produces a status of oxidative damage in the brain tissues which leads to cholinergic dysfunction as the acetylcholine levels show an inverse correlation with MDA equivalents [39]. BCLE elevated the SC-induced reduction in catalase activity, while it significantly reduced the MDA levels, indicating a powerful antioxidant effect of its phytoconstituents. 
BCLE effects on the cholinergic neurotransmission were evaluated by measuring the AChE levels. Acetylcholine is the neurotransmitter that plays an important role in memory regulations and learning abilities, its level is regulated by cholinergic enzymes in the neurons [39]. AChE is the enzyme that hydrolyzes acetylcholine, thus by inhibiting $\mathrm{AChE}$ a sufficient amount of acetylcholine will be retained in the brain tissue for proper cognitive function [40]. Raised levels of AChE as those induced by SC lead to mitochondrial dysfunction and thus elevated oxidative stress and memory decline [39]. Administration of BCLE concomitantly with SC recovered the normal AChE levels by decreasing the SC-induced elevation in its levels. Our results gave an indication that BCLE may exert its memory enhancing effect through modification of the cholinergic neurotransmission and restoration of the levels of brain antioxidants.

These results were further evidenced by the absence of histopathological alterations such as nuclear pyknosis, degeneration and eosinophilic plagues formation in the BCLE-group rats' neuronal tissue and restoration of the normal histological architecture of the rats' brain tissues that were altered by $\mathrm{SC}$ administration.

Phytochemical investigation of BCLE resulted in isolation and structural elucidation of $\beta$ sitosterol linoleate and $\beta$-amyrin. The former was isolated for the first time from the genus. GC-MS analysis of the leaves extract was carried out for the first time as well and it revealed the presence of the triterpenoids: $\beta$-amyrin, lupeol and olean-12-en-3-one; fatty acid esters such as methyl palmitate, sterols as stigmasterol acetate, diterpenes and hydrocarbons.

Several identified compounds were reported to have neuroprotective properties. Park et al. (2014) reported that $\beta$-amyrin can recover the SC-induced mice memory impairment through enhancement of the ERK (extracellular signal regulated kinase) and the GSK-3 $\beta$ (glycogen synthase kinase-3 $\beta$ ) signaling in the hippocampus, in addition to inhibiting AChE activity in vitro [41]. Stigmasterol was reported to possess neuroprotective activities in mice, in addition to protective effects against glutamate-induced toxicity in hippocampal HT-22 cell line by inhibiting both reactive oxygen species and calcium ion production [42, 43]. Kumar and Khanum (2012) reported the neuroprotective potential of $\alpha$-tocopherol [44]. Moreover, Kaundal et al. (2017) stated that lupeol ameliorates amyloid beta-induced neuronal damage in rats' brain tissues by improving the rats' behavior, restoring the levels of neurotransmitters, reducing oxidative stress and inflammation [45]. These results were confirmed by Badshah et al. (2016) who reported the neuroprotective effects of lupeol against lipopolysaccharide (LPS)-induced neural inflammation in mice brains through phosphorylation of p38 protein kinase and c-Jun $\mathrm{N}$-terminal kinase [46]. On the other hand, the long-term effects of linoleate-rich diet on increasing the aged rats learning abilities were reported [47]. Lin et al. (2014) reported that methyl palmitate and methyl stearate are released simultaneously from the sympathetic ganglion and that methyl palmitate has potential vasodilatory properties, especially in cerebral ischemia. In addition, both fatty acid esters can provide neuroprotection in focal and global cerebral ischemia in rats [48]. These results were further confirmed by Lee et al. (2016), who also stated that methyl esterification of fatty acids is related to neuroprotective abilities and vasodilation [49].

\section{Conclusion}

We conclude that, BCLE is rich in valuable phytoconstituents and has potential antioxidant and neuroprotective effects against Alzheimer-type dementia and memory impairment induced by SC. BCLE ameliorated both the behavioral and neurochemical parameters of the rats' brains, in addition to restoration of the normal histological architecture of the brain tissues. The leaves triterpenoids, fatty acid esters, and steroidal content may be responsible for ameliorating the oxidative stress and cholinergic dysfunction in the Alzheimer-type dementia induced by SC.

\section{Acknowledgements}

Thanks to Prof. Dr. Adel Kholoussy, Faculty of Veterinary Medicine, Cairo University, for histopathological examination of the rats' brain tissues; and to Dr. Esther Menze, Pharmacology and 
Toxicology Department, Faculty of Pharmacy, Ain Shams University, for carrying our rats' brain dissections.

\section{Supporting Information}

Supporting Information accompanies this paper on http://www.acgpubs.org/RNP

\section{ORCID}

Nada M. Mostafa: $\underline{0000-0003-1602-2725}$

\section{References}

[1] V. Rameshwar, D. Kishor, G. Tushar, G. Siddharth and G. Sudarshan (2014). A pharmacognostic and pharmacological overview on Bombax ceiba, Sch. Acad. J. Pharm. 3, 100-107.

[2] P. Y. Bhogaonka, Y. M. Rajgure and S. R. Kadu (2016). Nutritional and phytochemical profile of Bombax ceiba L. flowers - A wild edible, Int. J. Recent Sci. Res. 7, 13823-13825.

[3] M. M. Marzouk, S. R. Hussein, L. I. Ibrahim, A. Elkhateeb and S. A. Kawashty (2014). Flavonoids from Neurada procumbens L. (Neuradaceae) in Egypt, Biochem. Syst. Ecol. 57, 67-68.

[4] J. Refaat, S. Y. Desoky, M. A. Ramadan and M. S. Kamel (2013). Bombacaceae: A phytochemical review, Pharm. Biol. 51, 100-130.

[5] A. A. Shahat, R. A. Hassan, N. M. Nazif, S. V. Miert, L. Pieters, F. M. Hammuda and A. J. Vlietinck (2003). Isolation of mangiferin from Bombax malabaricum and structure revision of shamimin, Planta Med. 69, 1068-1070.

[6] S. Faizi and M. Ali (1999). Shamimin: A new flavonol C glycoside from leaves of Bombax ceiba, Planta Med. 65, 383-385.

[7] R. Saleem, M. Ahmad, S. A. Hussain, A. M. Qazi, S. I. Ahmad, M. H. Qazi, M. Ali, S. Faizi, S. Akhtar, and S. N. Husnain. (1999). Hypotensive, hypoglycaemic and toxicological studies on the flavonol C glycoside shamimin from Bombax ceiba. Planta Med. 65, 331-334.

[8] S. Faizi, S. ZikrurRehman, A. Naz, M. A. Versiani, A. Dar and S Naqvi (2012). Bioassay guided studies on Bombax ceiba leaf extract: isolation of shamimoside, a new antioxidant xanthone $\mathrm{C}$ glucoside, Chem. Nat. Compd. 48, 774-779.

[9] T. O. Vieira, A. Said, E. Aboutabl, M. Azzam and T. B. Creczynski-Pasa (2009). Antioxidant activity of methanolic extract of Bombax ceiba. Redox Rep. 14, 41-46.

[10] R. Tundis, K. Rashed, A. Said, F. Menichini and M. R. Loizzo (2014). In vitro cancer cell growth inhibition and antioxidant activity of Bombax ceiba (Bombacaceae) flower extracts, Nat. Prod. Commun. 9, 691.

[11] S. A. El-Toumy, U. W. Hawas and H. A.A.Taie (2013). Xanthones and antitumor activity of Bombax ceiba against ehrlich ascites carcinoma cells in mice, Chem. Nat. Compd., 49, 945.

[12] G. Singh, A. K. Passsari, V. V. Leo, V. K. Mishra, S. Subbarayan, B. P. Singh, B. Kumar, S. Kumar, V. K. Gupta, H. Lalhlenmawia and S. K. Nachimuthu (2016). Evaluation of phenolic content variability along with antioxidant, antimicrobial, and cytotoxic potential of selected traditional medicinal plants from India, Front. Plant Sci. 7, 407. doi: 10.3389/fpls.2016.00407.

[13] R. Anand, K. D. Gill and A. A. Mahdi (2014). Therapeutics of Alzheimer's disease: Past, present and future, Neuropharmacology 76, 27-50.

[14] S. Tota, C. Nath, A. K. Najmi, R. Shukla and K. Hanif. (2012). Inhibition of central angiotensin converting enzyme ameliorates scopolamine induced memory impairment in mice: role of cholinergic neurotransmission, cerebral blood flow and brain energy metabolism, Behav. Brain Res. 232, 66-76.

[15] H. Sugimoto, Y. Yamanishi, Y. Iimura, and Y. Kawakami. (2000). Donepezil hydrochloride (E2020) and other acetylcholinesterase inhibitors, Curr. Med. Chem. 7, 303-339.

[16] R. Kaur, S. Mehan, D. Khanna and S. Kalra. (2015). Ameliorative treatment with ellagic acid in scopolamine induced Alzheimer's type memory and cognitive dysfunctions in rats, Austin J. Clin. Neurol. 2, 1053.

[17] A. B. Singab, N. M. Mostafa, O. A. Eldahshan, M. L. Ashour and M Wink. (2014). Profile of volatile components of hydrodistilled and extracted leaves of Jacaranda acutifolia and their antimicrobial activity against foodborne pathogens, Nat. Prod. Commun. 9, 1007-1010. 
[18] N. M. Mostafa, O. A. Eldahshan and A. B. Singab. (2015). Chemical composition and antimicrobial activity of flower essential oil of Jacaranda acutifolia Humb. and Bonpl. against food-borne pathogens, European J. Med. Pl. 6, 62-69. doi: 10.9734/EJMP/2015/4749

[19] N. Ayoub, A. N. Singab, N. Mostafa and W. Schultze (2010). Volatile constituents of leaves of Ficus carica Linn. grown in Egypt, J. Essent. Oil Bear. Pl. 13, 316-321.

[20] F. Fernandes, P. B. Andrade, F. Ferreres, A. G.-Izquierdo, I. S.-Pinto and P. Valentao (2017). The chemical composition on fingerprint of Glandora diffusa and its biological properties, Arab. J. Chem. 10, 583-595

[21] Á. E. Daruházi, S. Szarka, É. Héthelyi, B. Simándi, I. Gyurján, M. László, É. Szőke and É. Lemberkovics (2008). GC-MS identification and GC-FID quantitation of terpenoids in Ononidis spinosae Radix, Chromatographia 68, 71-76.

[22] J. Asgarpanah, N. Dakhili, F. Mirzaee, M. Salehi, M. Janipour and E. Rangriz (2016). Seed oil chemical composition of Platychaete aucheri (Boiss.) Boiss, Pharmacogn. J. 8, 42-43.

[23] Y. J. Jang, J. Kim, J. Shim, C.-Y. Kim, J.-H. Jang, K. W. Lee and H. J. Lee (2013). Decaffeinated coffee prevents scopolamine-induced memory impairment in rats, Behav. Brain Res. 245, 113-119. doi: http://dx.doi.org/10.1016/j.bbr.2013.02.003

[24] H. Aebi (1984). Catalase in vitro, Method Enzymol. 105, 121-126.

[25] H. Ohkawa, W. Ohishi and K. Yagi. (1979). Assay for lipid peroxides in animal tissues by thiobarbituric acid reaction, Anal. Biochem. 95, 351-358.

[26] G. L. Ellman, K. D. Courtney, V. Jr. Andres and R. M. Featherstone (1961). A new and rapid colorimetric of acetylcholinesterase activity, Biochem. Pharmacol. 7, 88-95.

[27] J. D. Banchroft, A. Stevens and D. R. Turner (1996). Theory and practice of histological techniques. Fourth edn. Churchil Livingstone, New York.

[28] V. S. P. Chaturvedula and I. Prakash (2012). Isolation of stigmasterol and $\beta$-sitosterol from the dichloromethane extract of Rubus suavissimus, Int. Curr. Pharm. J. 1, 239-242.

[29] S.-P. Yang, J. Xu and J.-M. Yue (2003). Sterols from the fungus Catathelasma imperial, Chin. J. Chem. 21, 1390-1394.

[30] L. H. Vazquez, J. Palazon and A. N. Ocaña (2012). The pentacyclic triterpenes $\alpha$, $\beta$-amyrins: A review of sources and biological activities, In: Phytochemicals, A global perspective of the role in nutrition and health, ed: R.Venketeshwer, InTech, Croatia, pp.487-501.

[31] V. I. Babushok, P. J. Linstrom and I. G. Zenkevich (2011). Retention indices for frequently reported compounds of plant essential oils, J. Phys. Chem. Ref. Data 40, 043101-1-47.

[32] R. D. Jewart and J. Green (2005). Cognitive, behavioral, and physiological changes in Alzheimer's disease patients as a function of incontinence medications, Am. J. Geriatr. Psychiatry 13,324-328.

[33] P. Goverdhan, A. Sravanthi and T. Mamatha (2012). Neuroprotective effects of meloxicam and selegiline in scopolamine-induced cognitive impairment and oxidative stress, Int. J. Alzheimers Dis. 2012, 974013. doi: http://dx.doi.org/10.1155/2012/974013

[34] J. H. Oh, B. J. Choi, M. S. Chang and S. K. Park (2009). Nelumbo nucifera semen extract improves memory in rats with scopolamine-induced amnesia through the induction of choline acetyltransferase expression, Neurosci. Lett. 461, 41-44.

[35] J. S. Lee, S. S. Hong, H. G. Kim, H. W. Lee, W. Y. Kim, S. K. Lee and C. G. Son. (2016). GongjinDan enhances hippocampal memory in a mouse model of scopolamine-induced amnesia, PLoS ONE 11, e0159823. doi: 10.1371/journal.pone.0159823

[36] K. Jung, B. Lee, S. J. Han, J. H. Ryu and D.-H. Kim (2009). Mangiferin ameliorates scopolamineinduced learning deficits in mice, Biol. Pharm. Bull. 32, 242-246.

[37] N. Khosravi-Farsani, M. M. A. Boojar, Z. Amini-Farsani, S. Heydari and H. Teimori (2016). Antioxidant and antiglycation effects of scopolamine in rat liver cells, Pharm. Lett. 8,169-174.

[38] A. N. Singab, N. A. Ayoub, E. N. Ali and N. M. Mostafa (2010). Antioxidant and hepatoprotective activities of Egyptian moraceous plants against carbon tetrachloride-induced oxidative stress and liver damage in rats, Pharm. Biol. 48,1255-1264. doi: 10.3109/13880201003730659

[39] C. N. Du, A. Y. Min, H. J. Kim, S. K. Shin, H. N. Yu, E. J. Sohn, C.-W. Ahn, S. U. Jung, S.-H. Park and M. R. Kim (2015). Deer bone extract prevents against scopolamine-induced memory impairment in mice, J. Med. Food 18, 157-165. doi: 10.1089/jmf.2014.3187

[40] S. Palle and P. Neerati (2017). Quercetin nanoparticles attenuate scopolamine induced spatial memory deficits and pathological damages in rats, Bull. Fac. Pharm. Cairo Univ. 55, 101-106.

[41] S. J. Park, Y. J. Ahn, S. R. Oh, Y. Lee, G. Kwon, H. Woo, H. E. Lee, D. S. Jang, J. W. Jung and J. H. Ryu (2014). Amyrin attenuates scopolamine-induced cognitive impairment in mice, Biol. Pharm. Bull. 37, 1207-1213. 
[42] S. J. Park, D. H. Kim, J. M. Jung, J. M. Kim, M. Cai, X. Liu, J. G. Hong, C. H. Lee, K. R. Lee and J. H. Ryu (2012). The ameliorating effects of stigmasterol on scopolamine-induced memory impairments in mice, Eur. J. Pharmacol. 676, 64-70. doi: 10.1016/j.ejphar.2011.11.050

[43] J. W. Lee, J. B. Weon and C. J. Ma (2014). Neuroprotective activity of phytosterols isolated from Artemisia apiacea, Korean J. Pharmacogn. 45, 214-219.

[44] G. P. Kumar and F. Khanum (2012). Neuroprotective potential of phytochemicals, Pharmacogn. Rev. 6, 81-90. doi: 10.4103/0973-7847.99898

[45] M. Kaundal, M. Akhtar and R. Deshmukh (2017). Lupeol isolated from Betula alnoides ameliorates amyloid beta induced neuronal damage via targeting various pathological events and alteration in neurotransmitter levels in rat's brain, J. Neurol. Neurosci. 8, 195.

[46] H. Badshah, T. Ali, Shafiq-ur Rehman, Faiz-ul Amin, F. Ullah, T. H. Kim and M. O. Kim (2016). Protective effect of lupeol against lipopolysaccharide-induced neuroinflammation via the p38/c-Jun Nterminal kinase pathway in the adult mouse brain, J. Neuroimmune Pharmacol. 11,48-60. doi: 10.1007/s11481-015-9623

[47] N. Yamamoto, Y. Okaniwa, S. Mori, M. Nomura and H. Okuyama (1991). Effects of a high-linoleate and a high-alpha-linolenate diet on the learning ability of aged rats. Evidence against an autoxidationrelated lipid peroxide theory of aging, J. Gerontol. 46B, 17-22.

[48] H. W. Lin, I. Saul, V. L. Gresia, J. T. Neumann, K. R. Dave and M. A. Perez-Pinzon (2014). Fatty acid methyl esters and Solutol HS 15 confer neuroprotection after focal and global cerebral ischemia, Transl. Stroke Res. 5, 109-117. doi: 10.1007/s12975-013-0276

[49] R. H. C. Lee, J. J. G. Vasquez, A. C. E. Silva, D. D. Klein, S. E. Valido, J. A. Chen, F. M. Lerner, J. T. Neumann, C. Y. C. Wu and H. W. Lin (2016). Fatty acid methyl esters as a potential therapy against cerebral ischemia, $O C L$ 23D, 108. doi: 10.1051/ocl/2015040

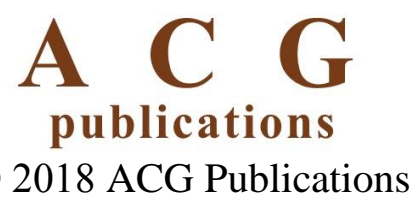

